\title{
Effect of dexamethasone on the endothelin-1 (ET-1) and endothelial nitric oxide synthase (eNOS) genes expression during hepatic warm ischemia/reperfusion in rat
}

\author{
Kasra Ghanaat ${ }^{1}$, Amir valizadeh-Dizajeykan ${ }^{1}$, Majid Malekzadeh-Shafaroudi ${ }^{2}$, Ali Gohari ${ }^{3}$, Abbas Khonakdar-Tarsi ${ }^{4 *}$ \\ ${ }^{1}$ MSc Student in Biochemistry, Faculty of Medicine, Mazandaran University of Medical Sciences, Sari, Iran. \\ ${ }^{2}$ Assistant Professor, Department of Anatomy, Mazandaran University of Medical Sciences, Sari, Iran. \\ ${ }^{3}$ PhD Student; Department of Biochemistry, School of Medicine, Shiraz University of Medical Sciences, Shiraz, Iran. \\ ${ }^{4}$ Assistant Professor, Department of Biochemistry and Genetics, Faculty of Medicine, Mazandaran University of Medical Sciences, Sari, Iran.
}

Received: 22 Aug 2016

Revised : 27 Sep 2016

Accepted: 12 Oct

Corresponding Author: Abbas Khonakdar-Tarsi Assistant Professor, Department of Biochemistry and Genetics, Faculty of Medicine, Mazandaran University of Medical Sciences, Sari, Iran Phone: +989112235164

E-mail: khonakdarab@gmail.com

\begin{abstract}
Background: Hepatic ischemia/reperfusion injury (I/RI) is a multifactorial pathophysiologic process which can lead to liver damage and dysfunction. This study examined the protective effect of dexamethasone on the gene expression of endothelial nitric oxide synthase (eNOS) and endothelin-1 (ET-1) and on the liver tissue damage during warm hepatic I/R.

Materials and Methods: A total of 32 male Wistar rats was randomly divided into four groups of eight: SHAM: the group receiving saline; DEX: the group receiving dexamethasone $(8 \mathrm{mg} / \mathrm{kg})$; I/R: Ischemia-reperfusion insulted group; and $\mathrm{DEX}+\mathrm{I} / \mathrm{R}$ : I/R group receiving dexamethasone. After $3 \mathrm{~h}$ of reperfusion followed by $60 \mathrm{~min}$ of ischemia, serum and ischemic tissue were collected. Serum was used to determine the hyaluronic acid (HA), aspartate and alanine aminotransferases (AST and ALT). To evaluate the eNOS and ET-1 gene expression, the total RNA was extracted from the liver tissue, cDNA was synthesized and real-time PCR was performed. Tissue staining was performed by the Hematoxylin and Eosin stain.

Results: I/R increased serum AST, ALT and HA in I/R group compared with that in the SHAM group $(\mathrm{P}<0.001)$. Dexamethasone significantly reduced the indicators in DEX + IR group $(\mathrm{P}<0.001)$. In addition, the gene expression of the eNOS and ET-1 increased during I/R. Dexamethasone could significantly decrease the ET-1, but not eNOS gene expression in the DEX + IR group.

Conclusion: Dexamethasone can decline hepatic I/RI by protecting the sinusoidal endothelial glycocalyx and modifying the expression of ET-1. Given that the reactive oxygen species (ROS) are the main cause of glycocalyx degradation and ET-1 is the regulator of hepatic perfusion, thus, dexamethasone has antioxidant properties and helps proper hepatic perfusion after ischemia to maintain.
\end{abstract}

Keywords: Ischemia; Reperfusion; Glycocalyx; Endothelin-1

Please cite this article as: Ghanaat K, Valizadeh-Dizajeykan A, Malekzadeh-Shafaroudi M, Gohari A, Khonakdar-Tarsi A. Effect of dexamethasone on the endothelin-1 (ET-1) and endothelial nitric oxide synthase (eNOS) genes expression during hepatic warm ischemia/reperfusion in rat. Res Mol Med. 2016; 4 (4): 8-14

\section{Introduction}

Hepatic ischemia/reperfusion injury (I/RI) is commonplace in liver transplantation, resection, infection, trauma, shock and haemorrhage. Microcirculation failure is one of the main causes of liver dysfunctions during I/R (1). It has been reported that endothelin-1 (ET-1) and nitric oxide (NO) are the two master regulators of the liver perfusion in normal conditions. A delicate balance between the production of these two regulators in the I/R -insulted liver is disturbed, in a way that the gene expression of ET-1 and endothelial NO synthase (eNOS) elevates (2). On the other hand, during reperfusion, direct cellular damages occur by reactive oxygen species (ROS), which react with cellular components, 
stimulate the synthesis of pro-inflammatory mediators and ultimately cause liver failure along with other intricate mechanisms (3). One of the most important targets of ROS is the endothelial cell surface glycocalyx. In normal conditions, the endothelial glycocalyx plays an active role in maintaining the vascular homeostasis by preventing the leakage of blood proteins and infiltration of cells into the hepatic tissue (4). Dexamethasone, a member of glucocorticoid anti-inflammatory drugs, has been used to reduce various types of inflammations in which the main known mechanism is the inhibition of the phospholipase A2 and of the prostaglandin pathway. Considering the complexity of I/RI mechanism and the diversity of drug functions, the aim of this study was to investigate the effect of dexamethasone on the eNOS and ET-1 gene expression and on the glycocalyx injury during warm hepatic I/R.

\section{Materials and methods}

In total, 32 male Wistar rats, weighting 220-250 g, were randomly selected from the animal studies center in Mazandaran University of Medical Sciences. The animals were housed at a temperature of $25 \pm 1{ }^{\circ} \mathrm{C}$ and humidity of $55 \pm 5 \%$, with light and dark cycle of $12 \mathrm{~h}$. Ethical issues were considered about the use of laboratory animals intraoperatively; causing no pain and suffering to the animals was also taken into account.

The rats were randomly divided into four groups of eight:

1. The control group (SHAM) received $0.9 \%$ saline with surgery.

2. The group that received dexamethasone (DEX) with surgery.

3. The group of $I / R$, received saline (I/R).

4. The group of $I / R$, received dexamethasone (DEX + I/R).

The rats were fasted for $18 \mathrm{~h}$ preoperatively but water was available. The rats were anaesthetized with Ketamine $(60 \mathrm{mg} / \mathrm{kg}$, i.p) and xylazine $(10 \mathrm{mg} / \mathrm{kg}$, i.p). The left branches of the portal vein and the hepatic artery were blocked with bulldog clamps for full ischemia of the middle and left hepatic lobes; the right lobe was not blocked to prevent intestinal congestion (5). After 60 min of ischemia, clamp was removed to restore blood flow. Through I/R, the liver was kept with a moist saline gauze to prevent the animal from dehydrating. After $1 \mathrm{~h}$ the clamp was removed and the liver was transferred into the abdominal cavity and the incision was sutured. The control animals were prepared in a similar way except for the clamp that was not used. After $3 \mathrm{~h}$ of reperfusion, the rats were killed; serum and ischemic tissue were collected, and at the time of testing, were stored at $-70{ }^{\circ} \mathrm{C}$. Dexamethasone was injected intraperitoneally twice at a dose of $8 \mathrm{mg} / \mathrm{kg}$, exactly $60 \mathrm{~min}$ before ischemia and immediately after reperfusion.

\section{Extraction and Purification of RNA}

Cellular RNA was isolated from liver tissues using the RNeasy plus mini kit (Qiagen, Ger) as per the manufacturer's instructions. The concentration and purity of RNA were determined by a UV spectrophotometer (Biowave II WPA, biochrom, England) at a wavelength of $260 / 280 \mathrm{~nm}$ ratio in $\mathrm{ng} / \mu \mathrm{L}$. Quality of purified RNA was evaluated by $1.5 \%$ agarose gel electrophoresis with SYBR Green to determine the integrity of RNA.

\section{Relative expression of eNOS and ET-1 genes using real-time PCR}

To assess the relative gene expression, cDNA was synthesized by extracted RNA $(1 \mu \mathrm{g})$ and reverse transcriptase enzyme (Qiagen, Ger). Real-time PCR was performed to quantify the candidate mRNA genes using the related kit (Qiagen, Ger) and specific primers (Table 1).

Table 1. Specific primer sequences for eNOS, ET-1 and $\beta$-actin. The primers were designed and synthesized by software Allel ID7 according to the related gene sequence

\begin{tabular}{lll}
\hline Gene & Primer sequence $\mathbf{5}^{\prime} \rightarrow \mathbf{3}^{\prime}$ & Product length (bp) \\
\hline \multirow{2}{*}{ Edn1 } & Sense : AGCACATTGACTACAGAGC & 212 \\
& Antisense: ACGAAGACAGGTTAGGGAA & 149 \\
Nos3 & Sense : CAGGCTCTCACTTACTTCC & 145 \\
& Antisense: AACCACTTCCATTCTTCGTA & 145 \\
$\beta$-actin & Sense : 5'-CCCATCTATGAGGGTTACGC-3' \\
& Antisense: 5'-TTTAATGTCACGCACGATTTC-3'
\end{tabular}

SYBR Green PCR Master Mix reagent (Qiagen, Ger), approximately $50 \mathrm{ng}$ of the cDNA and $10 \mu \mathrm{M}$ of each primer in a total volume of $20 \mu \mathrm{L}$ were subjected to real-time PCR. Step-One-PlusTM real- time (Rotor- Gene ${ }^{\circledR}$ Q) was used to perform the reactions. Uracil-N-glycosylase (UNG) was used to avoid contamination; UNG destroyed all of the nonspecific PCR products that contained dUMP. The 
cycling conditions were set up as primary activation and denaturation for $10 \mathrm{~min}$ at $95{ }^{\circ} \mathrm{C}$ and 40 cycles for $15 \mathrm{~s}$ at $94{ }^{\circ} \mathrm{C}, 30 \mathrm{~s}$ at $70{ }^{\circ} \mathrm{C}$, and $30 \mathrm{~s}$ at $72{ }^{\circ} \mathrm{C}$. The standard curves were used to monitor all assay efficiencies. The $\beta$-actin housekeeper gene was used to normalize the outcome threshold cycles (CTs) and as an internal standardization control.

\section{Measurement of Hyaluronic Acid}

Measurement of HA (ng/ml) serum levels is a suitable method to assess glycocalyx damages of the liver tissue. HA was determined by an ELISA kit according to the manufacturer's protocol (R\&D systemsTM a bio-techno brand, USA).

\section{Aspartate aminotransferase and alanine} aminotransferase activity

To determine the severity of liver parenchymal cell damage, serum levels of ALT and AST activity (U/L) were measured by the Pars azmoon kit (Karaj, Iran), the manufacturer's protocol was performed using an automated chemical analyzer (BT-3000-plus, Biotechnica, Italy).

\section{Histopathological studies of liver tissue}

Five micron slices of liver tissues were prepared by microtome after being fixed in $10 \%$ formalin; the sections' staining was performed using the Hematoxylin and Eosin stain.

\section{Statistics analysis}

All results of aminotransferases and HA are expressed as mean \pm standard error of mean (mean \pm S.E.M). The mean difference between groups was determined by one-way ANOVA and Tukey multiple comparison test using SPSS ver. 13; the level of P < 0.05 was considered as significant. Real-time PCR results were analysed using Linreg and Rest-rg software.

\section{Results}

\section{Liver parenchymal cells damage}

Increased levels of serum ALT and AST activities reflect the destruction of liver parenchymal cells. The mean values of ALT and AST in the SHAM group were $67.33 \pm 4.23 \mathrm{U} / \mathrm{L}$ and $245.6 \pm 23.61 \mathrm{U} / \mathrm{L}$, respectively (Figures 1 and 2).

Levels of this aminotransferases significantly increased $(\mathrm{P}<0.001)$ in the $\mathrm{I} / \mathrm{R}$ group to 633.42 $\pm 41.58 \mathrm{U} / \mathrm{L}$ and $983.7 \pm 66.42 \mathrm{U} / \mathrm{L}$, respectively. A noteworthy decrease of ALT and AST levels was observed after the administration of dexamethasone in DEX + IR, $274.55 \pm 25.44 \mathrm{U} / \mathrm{L}$ for ALT and 257.5 $\pm 27.45 \mathrm{U} / \mathrm{L}$ for AST $(\mathrm{P}<0.001)$ compared with that in the $\mathrm{I} / \mathrm{R}$ group. No significant differences were observed between DEX and SHAM groups $(\mathrm{P}>0.05)$.

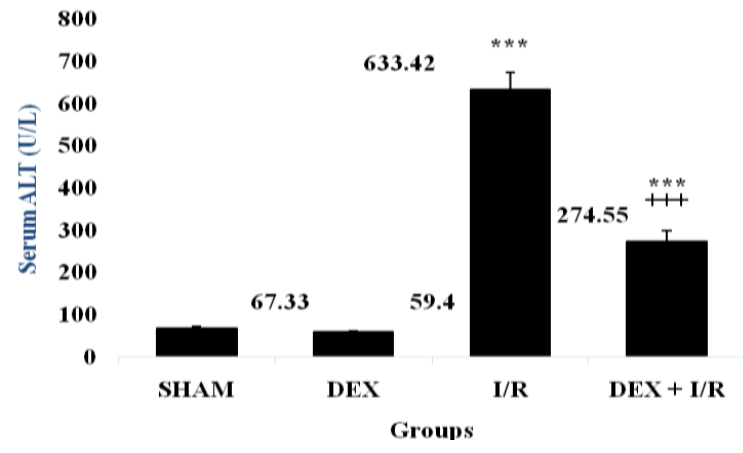

Figure 1. The effect of dexamethasone on serum ALT activity during I/R. The values are expressed by mean \pm SEM. The level of significance was considered as less than $0.05(\mathrm{P}<0.05)$. +++ Significantly different from the control group $(\mathrm{P}<0.001)$. ***Significantly different from the $\mathrm{I} / \mathrm{R}$ group $(\mathrm{P}<0.001)$. SHAM: the group receiving saline; DEX: the group receiving dexamethasone; I/R: Ischemia-reperfusion insulted group; DEX + I/R: I/R group receiving dexamethasone.

Damage of sinusoidal endothelial glycocalyx As it can be seen in Figure 3, the levels of HA significantly increased $(\mathrm{P}<0.001)$ in $\mathrm{I} / \mathrm{R}(55.61 \pm$ $5.23 \mathrm{ng} / \mathrm{ml}$ ) compared with those in the SHAM and DEX groups. After the injection of dexamethasone in DEX + IR, HA levels significantly decreased to 13.45 $\pm 1.44 \mathrm{ng} / \mathrm{ml}(\mathrm{P}<0.001)$.

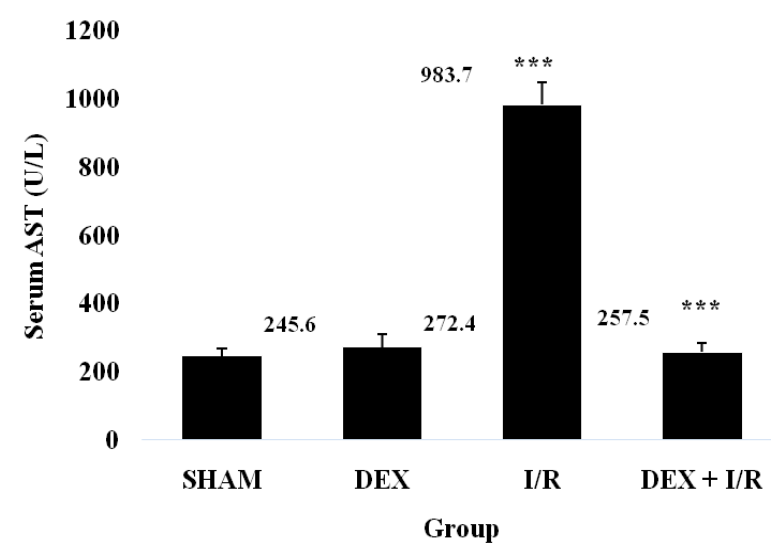

Figure 2. The effect of dexamethasone on serum AST activity in the studied groups. The values are expressed by mean \pm SEM. The level of significance was considered as less than $0.05(\mathrm{P}<0.05)$. +++ Significantly different from the control group $(\mathrm{P}<0.001) . * * *$ Significantly different from the I/R group $(\mathrm{P}<0.001)$. SHAM: the group receiving saline; $\mathrm{DEX}$ : the group receiving dexamethasone; I/R: Ischemia-reperfusion insulted group; $\mathrm{DEX}+\mathrm{I} / \mathrm{R}$ : I/R group receiving dexamethasone.

\section{eNOS gene expression}

eNOS gene expression analysis is shown in Figure 4. Compared with the SHAM and DEX groups, the eNOS gene expression in the I/R group, showed a significant increase $(\mathrm{P}<0.001)$. eNOS mRNA expression in $\mathrm{DEX}+\mathrm{I} / \mathrm{R}$ did not significantly increase as a result of treatment with dexamethasone ( $\mathrm{P}$ $>0.05$ ). 


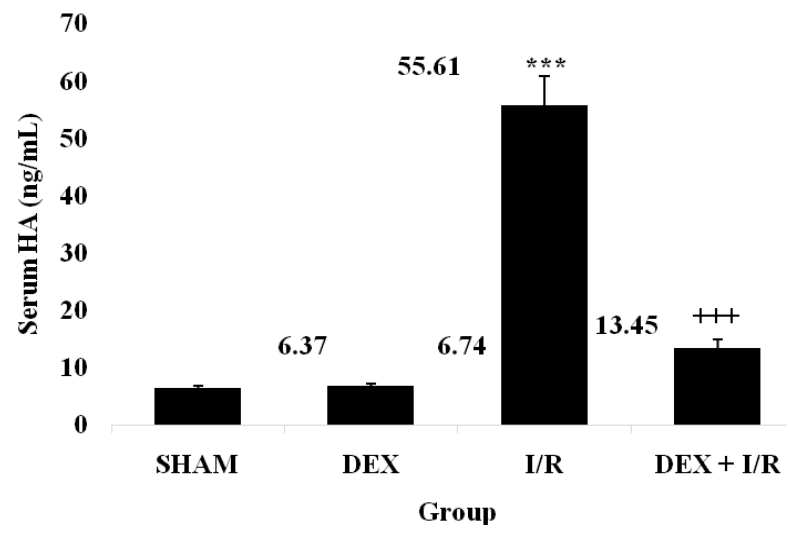

Figure 3. Changes in mean serum HA in the four studied groups. The values are expressed by mean \pm SEM. The level of significance was considered as less than $0.05(\mathrm{P}<0.05)$. +++ Significantly different from the control group $(\mathrm{P}<0.001)$. *** Significantly different from the $\mathrm{I} / \mathrm{R}$ group $(\mathrm{P}<0.001)$. SHAM: the group receiving saline; DEX: the group receiving dexamethasone; $\mathrm{I} / \mathrm{R}$ : Ischemia-reperfusion insulted group; DEX + I/R: I/R group receiving dexamethasone.

\section{Gene expression of ET-1}

Changes in ET-1 gene expression are shown in Figure 5. ET-1 expression in group I/R, in compared with that in SHAM and DEX groups, showed a significant increase $(\mathrm{P}<0.001)$. But ET-1 mRNA expression in $\mathrm{DEX}+\mathrm{I} / \mathrm{R}$ significantly declined $(\mathrm{P}<0.001)$.

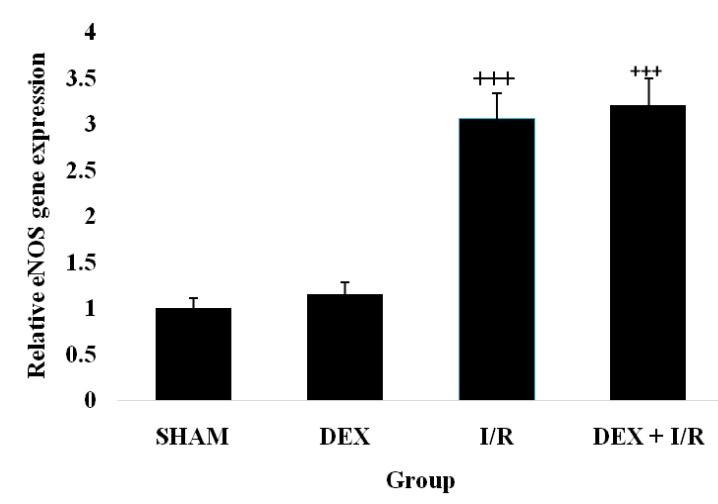

Figure 4. Comparisons of relative eNOS gene expression between the four groups studied. The values are expressed by mean \pm SEM. The level of significance was considered as less than 0.05 ( $\mathrm{P}<$ $0.05)$. +++ Significantly different from the control group $(\mathrm{P}<$ 0.001). SHAM: the group receiving saline; DEX: the group receiving dexamethasone; I/R: Ischemia-reperfusion insulted group; DEX + I/R: I/R group receiving dexamethasone.

\section{Liver Histopathology}

Liver cells with round, bright nuclei and clear nucleoli were observed as cell cords in the SHAM group. Hepatic sinusoids, the lining of the liver central venous endothelium and the Kupffer cell (white arrows) density were normal.

Sinusoidal endothelium (tetramerous stars) and the central veins of lobules (pentagram) were also clearly seen. Cells in area 3 of the liver's classic lobule (close to the central vein), known as ischemic area and as a marker of liver healthiness, were highly healthy. In zone 1, hepatocytes mainly with darker nuclei and more colorable cytoplasm were visible (Figure 6 A).

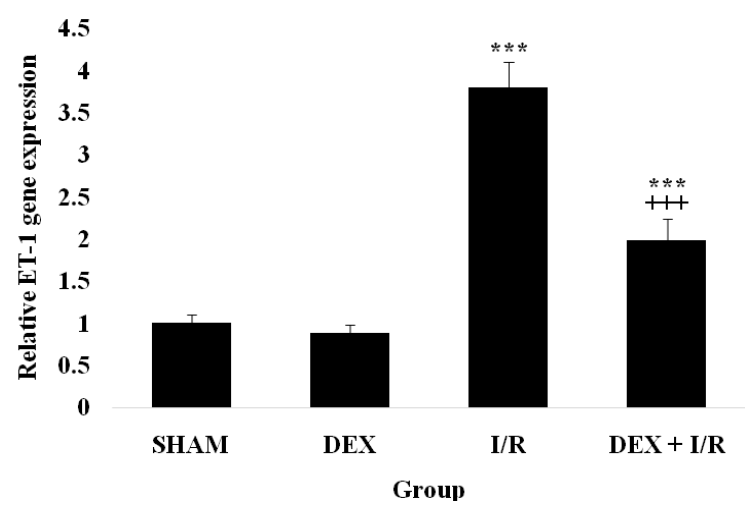

Figure 5. Comparisons of relative ET-1 gene expression between the four groups studied. The values are expressed by mean \pm SEM. +++ Significantly different from the control group $(\mathrm{P}<0.001)$. The level of significance was considered as less than $0.05(\mathrm{P}<0.05)$. ***Significantly different from the I/R group $(\mathrm{P}<0.001)$. SHAM: the group receiving saline; DEX: the group receiving dexamethasone; I/R: Ischemia-reperfusion insulted group; DEX + I/R: I/R group receiving dexamethasone

In the DEX (dexamethasone without ischemia) group, hepatocytes with clear nuclei and bright nucleoli were observed, particularly in area 3. Liver sinusoids were clear and a large number of Kupffer cells (containing swallowed dark granules) were observed in sinusoidal spaces (SP) with more density than the control group. Vascular endothelial often showed arterial loss or its damage, whether in sinusoidal spaces or in central vein (pentagram) (Figure 6 B).

In the third group ( $\mathrm{I} / \mathrm{R}$, receiving saline with ischemia), hepatic cords in many sectors were discrete in all three zones. With higher magnification, hepatocytes atrophy could be clearly seen in regions 1 and 3, which indicates the destruction of liver tissues in each area. The wide activities of Kupffer cells (white arrows) were impressive to swallow and digest damaged cells. The vascular endothelium was often injured. Leukocyte infiltration and Kupffer cells swallowing with a large number of dark pigments were visible in the liver sinusoids. Sombrous giant cells (diamond) with red cytoplasmic and spherical nucleus were observed out of the centre in the sinusoidal space and also in lobular central veins (Figure 6 C).

In the fourth group $(\mathrm{DEX}+\mathrm{I} / \mathrm{R}$, receiving dexamethasone with ischemia), hepatocytes were seen in zone 1, indicating that the liver classic lobule 
was almost injured and nuclei was pushed to the side, but all nuclei with obvious nucleoli were round and clear. In zone 3 close to the central vein, the cells showed healthy morphology. However, in zone 2 of the classic lobules, symptoms of irritation could be seen as a hepatocytes vacuolization and the loss of some cell boundaries. A pink cerevisiae secrete could be visualized in the vascular spaces of the central vein (pentagram). Leukocytes (granulocytes) infiltration (dark triangle) with a large number of activated Kupffer cells (white arrows) were observed in the SP (Fig. 6 D).

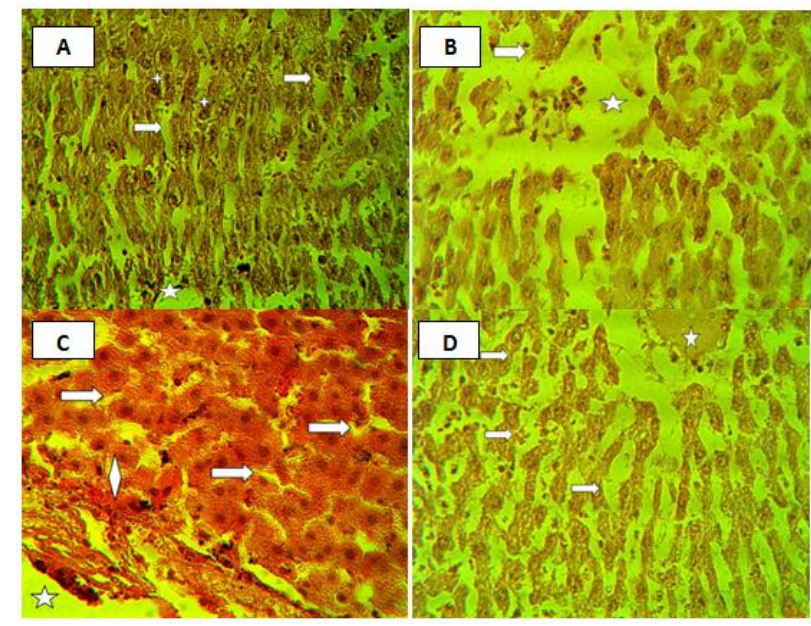

Figure 6. Comparison of the liver histological sections in the four studied groups (H \& E, magnification 400X). CV: Central venule; white arrow: Kupffer cell; sinusoidal endothelium: tetramerous stars; central veins: pentagram; SP: sinusoidal space; granulocytes: dark triangle.

\section{Discussion}

I/R-induced liver injury is the main complication of liver transplantation, trauma, shock, and resection. Interruption of blood flow, oxygen deprivation in the phase of ischemia and complicated molecular changes start with ischemia and continue during reperfusion, finally destroying the hepatocytes (4). In early stages of I/R ( $<2 \mathrm{~h}$ after reperfusion), Kupffer cells and damaged hepatocytes release ROS and cause limited damage. However, as a result of oxidative stress during reperfusion, the production of several pro-inflammatory cytokines such as TNF- $\alpha$, IL-12, and IL-1 $\beta$, which are triggered in the ischemic phase, increases drastically $(3,6,7)$. At this stage of inflammatory reaction, activated neutrophils enter the liver tissue, release more ROS and inflammatory factors and cause further damage to hepatocytes (8). Therefore, the presence and the key role of ROS and inflammatory markers have been demonstrated in numerous studies (9).

Furthermore, disruption of the sinusoidal blood flow is another reason for the I/RI. Liver microcirculation is normally set by the careful balance between vasoconstrictors (particularly ET-1) and vasodilators (NO and $\mathrm{CO}$ ); however, in the I/R-insulted liver, this balance is disturbed and hepatic perfusion is impaired. ET-1 is a potent vasoconstrictor peptide that binds to ETA receptor (10). ETA receptors are present in all cells, but their presence in liver stellate cells is more than other sinusoidal cells and hepatocytes. The contraction of stellate cells regulates the dilation of sinusoids (10). ET-1 reduces the microscopic blood flow of liver by binding to this type of a receptor and can consequently cause I/RI (11). It is evident that the ET-1 increases portal vein pressure, liver glycogenolysis and changes the oxygen consumption. Zhang et al studied the human trabecular mesh-work cells and found that dexamethasone reduced ETB and ET-1 receptor protein expression and simultaneously increased the level of NO (12). Our results showed that $I / R$ elevated ET-1 gene expression and caused the destruction of liver tissue. This harmful change, in addition to the increasing levels of ALT and AST, was confirmed by the elevated levels of HA. The release of HA indicated that the glycocalyx of sinusoidal endothelial surface was destroyed by oxidative stress during reperfusion. Dexamethasone could significantly reduce the expression of ET-1 during I/R and through the inhibition of the sinusoids contraction and improvement of hepatic perfusion, decrease liver I/RI. As it could be seen in histological pictures, dexamethasone had protective effects on liver tissue. Ghobadi et al. also observed that dexamethasone, in addition to ALT and AST, significantly reduced iNOS gene expression during liver $I / R$ (13). In a similar study, Amr et al. demonstrated that dexamethasone significantly decreased the TNF- $\alpha$ gene expression (14).

On the other hand, as a biological signaling molecule, $\mathrm{NO}$ is mainly considered as a vasodilatory and endothelium-dependent relaxing factor (15). It is essential to maintain normal perfusion of sinusoids and the low amounts produced by eNOS will suffice for ensuring a normal perfusion in healthy liver. Its production by eNOS plays a key role in the alleviation of severity of cell damage during I/R (16). Typically, eNOS is considered as a housekeeping enzyme that is regulated by post-translational modifications; calcium/calmodulin and the amount of its protein can also be increasingly set by stimulants such as shear stress (17). Rats treated with the inhibitors of eNOS have the liver damage speed up by stresses such as endotoxin injection $(18,19)$. During I/R, activated endothelial and Kupffer cells and infiltrated neutrophils produce large amount of ROS that can inhibit NO synthesis and generate several active radicals, named RNS, through reaction 
with NO, reducing the accessibility to NO (20). Numerous studies confirmed the protective role of eNOS-derived NO against I/R injury (21-23). Some studies showed that due to the low concentration of eNOS, stable levels of NO are reduced during I/R (24-26), which subsequently increase in the oxidative stress, apoptosis, adhesion of leukocytes and the occurrence of mitochondrial dysfunctions (27).

Therefore, eNOS-derived NO is required to maintain hepatic normal perfusion (28). Current study suggested that dexamethasone injection increased expression of eNOS gene and its protective role against hepatic I/R. These effects occur in three ways: 1) Countering the vasoconstrictory effect of ET-1;2) inhibiting the neutrophil adhesion or migration; and 3 ) inhibiting the platelet aggregation. Bobadilla et al. showed the effect of dexamethasone on the increased production of NO resulted from eNOS gene expression in preventing renal vasoconstriction caused by cyclosporin A (29). Ali et al. also noted the protective effect of corticosteroid drugs, such as dexamethasone, in acute cardiovascular disease through the activation and elevation of eNOS gene expression (28).

Rubio-Gayoso et al. showed that ROS production at a high speed is the main cause of glycocalyx damage during I/R. In addition, the glycocalyx components not only have a protective role on endothelial cells but also a central duty in the damage of small blood vessels in I/R. HA plays a key role in the structure of sinusoidal endothelial surface glycocalyx, which is released as a result of its destruction by ROS (30). As it was shown in our results, serum hyaluronic acid increased during $\mathrm{I} / \mathrm{R}$, so it can be concluded that the sinusoidal glycocalyx was damaged and the hyaluronan was released into the blood. Glucocorticoids can limit the inflammatory damage to the glycocalyx by suppressing the production of cytokines and chemokines and also through preventing the infiltration of inflammatory cells into tissues and mast cell degranulation. In a sample of isolated heart, hydrocortisone was able to significantly inhibit destruction of the endothelial surface layer after ischemia and during reperfusion and reduce TNF- $\alpha$ induction (31). In this study, we demonstrated that dexamethasone reduced parenchymal cell injury (reduction of ALT and AST) and also significantly ameliorated the glycocalyx damage in the group DEX + IR. Thus, it can be concluded that dexamethasone can prevent the destruction of glycocalyx probably by indirect antioxidative role and consequently prevents sinusoidal endothelial cell damage and penetration of the proteins and neutrophils out of the sinusoid. Greenwald et al. found that neutrophils destroyed the hyaluronic acid of synovial fluid by producing ROS
(30). Taghizadieh et al. also showed that dexamethasone reduced the production of MDA and maintained the level of the antioxidant enzyme in liver during I/R (31). Dexamethasone ameliorates MDA, so it indirectly exerts an antioxidative effect, which can be confirmed by our results.

In this study, histological analyses showed that dexamethasone significantly reduced the amount of tissue damage, which was consistent with the reduced levels of serum aminotransferases and HA. Also, treatment with dexamethasone could reduce tissue damage during I/R on rat liver (14).

Finally, it can be concluded that dexamethasone reduces the I/RI through different mechanisms, including the prevention of the damage of liver sinusoidal endothelial glycocalyx and parenchymal cell by inhibiting ROS production. In addition, reduction in the ET-1 and increment in the eNOS gene expression helps the liver to establish proper blood flow during reperfusion.

\section{Acknowledgments}

The authors wish to thank the Cellular and Molecular Biology Research Center in Mazandaran University of Medical Sciences who provided financial support for the conduct of the study.

\section{Conflict of interest}

The author declare no conflicts of interest.

\section{References}

1. Peralta C, Jiménez-Castro MB, Gracia-Sancho J. Hepatic ischemia and reperfusion injury: effects on the liver sinusoidal milieu. J Hepatol. 2013; 59(5):1094-106. PMID: 23811302

2. Abu-Amara M, Yang SY, Tapuria N, Fuller B, Davidson B, Seifalian A. Liver ischemia/reperfusion injury: processes in inflammatory networks-a review. Liver Transpl. 2010; 16(9):1016-32. PMID: 20818739

3. Jaeschke $H$, Hasegawa $T$. Role of neutrophils in acute inflammatory liver injury. Liver Int. 2006; 26(8):912-9. PMID; 16953830

4. van Golen RF, van Gulik TM, Heger M. Mechanistic overview of reactive species-induced degradation of the endothelial glycocalyx during hepatic ischemia/reperfusion injury Free Radic Biol Med. 2012; 52(8):1382-402. PMID: 22326617

5. Adam ANI. Some mechanisms of the protective effect of ischemic preconditioning on rat liver ischemia-reperfusion injury. Int J Gen Med. 2014; 7:483. PMID: 25382983

6. Lentsch AB, Kato A, Yoshidome H, McMasters KM, Edwards MJ. Inflammatory mechanisms and therapeutic strategies for warm hepatic ischemia/reperfusion injury. Hepatology. 2000; 32(2):16973. PMID: 10915720

7. Teoh NC. Hepatic ischemia reperfusion injury: contemporary perspectives on pathogenic mechanisms and basis for 
hepatoprotection-the good, bad and deadly. J Gastroenterol Hepatol. 2011; 26(s1):180-7. PMID: 21199530

8. Teoh NC, Farrell GC. Hepatic ischemia reperfusion injury: pathogenic mechanisms and basis for hepatoprotection. . J Gastroenterol Hepatol. 2003; 18(8):891-902. PMID: 12859717

9. Simons SS. What goes on behind closed doors: physiological versus pharmacological steroid hormone actions. Bioessays. 2008; 30(8):744-56. PMID: 18623071

10. Ergul A. Endothelin-1 and endothelin receptor antagonists as potential cardiovascular therapeutic agents. Pharmacotherapy. 2002; 22(1):54-65. PMID: 11794430

11. El-Sherif AM, Abou-Shady MA, Al-Bahrawy AM, Bakr RM, Hosny A-MM. Nitric oxide levels in chronic liver disease patients with and without oesophageal varices. Hepatol Int. 2008; 2(3):3415. PMID: 19669263

12. Zhang $X$, Clark AF, Yorio T. Interactions of endothelin-1 with dexamethasone in primary cultured human trabecular meshwork cells. Invest Ophthalmol Vis Sci. 2003; 44(12):5301-8. PMID: 14638730

13. Ghobadi M, Ghanaat K, Valizadeh-Dizgikan A, Gohari G, Roadi B, Khonakdar-Tarsi A. The Effect of Dexamethasone on Expression of Inducible Nitric Oxide Synthase Gene During Liver Warm Ischemia-reperfusion in Rat. Res Mol Med. 2015; 3(3):1722

14. Fouad AA, El-Bidawy MH, Uddin AM, Yacoubi MT. A preliminary study of dexamethasone against ischemia/reperfusion liver injury in rats. Int J Pharmacol. 2009; 5(2):155-61.

15. Topper JN, Cai J, Falb D, Gimbrone MA. Identification of vascular endothelial genes differentially responsive to fluid mechanical stimuli: cyclooxygenase-2, manganese superoxide dismutase, and endothelial cell nitric oxide synthase are selectively up-regulated by steady laminar shear stress Proc Natl Acad Sci U S A. 1996; 93(19):10417-22. PMID: 8816815

16. Harbrecht B, Billiar T, Stadler J, Demetris A, Ochoa J, Curran $\mathrm{R}$, et al. Inhibition of nitric oxide synthesis during endotoxemia promotes intrahepatic thrombosis and an oxygen radical-mediated hepatic injury. J Leukoc Biol. 1992; 52(4):390-4. PMID: 1328440

17. Harbrecht BG, Wu B, Watkins SC, Marshall Jr HP, Peitzman $\mathrm{AB}$, Billiar TR. Inhibition of nitric oxide synthase during hemorrhagic shock increases hepatic injury. Shock. 1995; 4(5):332-7. PMID: 8595519

18. Cottart CH, Do L, Blanc MC, Vaubourdolle M, Descamps G, Durand D, et al. Hepatoprotective effect of endogenous nitric oxide during ischemia-reperfusion in the rat. Hepatology. 1999; 29(3):809-13. PMID: 10051483

19. Tsao PS, Lefer AM. Time course and mechanism of endothelial dysfunction in isolated ischemic-and hypoxic-perfused rat hearts. Am J Physiol. 1990; 259(6):H1660-H6. PMID: 2260693
20. Koti RS, Tsui J, Lobos E, Yang W, Seifalian AM, Davidson BR. Nitric oxide synthase distribution and expression with ischemic preconditioning of the rat liver. FASEB J. 2005; 19(9):1155-7. PMID: 15870170

21. Duranski MR, Elrod JW, Calvert JW, Bryan NS, Feelisch M, Lefer DJ. Genetic overexpression of eNOS attenuates hepatic ischemia-reperfusion injury. Am J Physiol Heart Circ Physiol. 2006; 291(6):H2980-H6. PMID: 16877550

22. Katsumi H, Nishikawa M, Yamashita F, Hashida M Prevention of hepatic ischemia/reperfusion injury by prolonged delivery of nitric oxide to the circulating blood in mice. Transplantation. 2008; 85(2):264-9. PMID: 18212632

23. Ling H, Edelstein C, Gengaro P, Meng X, Lucia S, Knotek M, et al. Attenuation of renal ischemia-reperfusion injury in inducible nitric oxide synthase knockout mice. Am J Physiol. 1999; 277(3):F383-F90. PMID: 10484522

24. Clemens MG. Nitric oxide in liver injury. Hepatology. 1999; 30(1):1-5. PMID: 10385631

25. Hines IN, Harada H, Flores S, Gao B, McCord JM, Grisham MB. Endothelial nitric oxide synthase protects the post-ischemic liver: potential interactions with superoxide. Biomed Pharmacother. 2005; 59(4):183-9. PMID: 15862713

26. Redondo J, Manso AM, Pacheco ME, Hernández L, Salaices M, Marín J. Hypothermic storage of coronary endothelial cells reduces nitric oxide synthase activity and expression. Cryobiology. 2000; 41(4):292-300. PMID: 11222026

27. Bobadilla NA, Tapia E, Jiménez F, Sánchez-Lozada LG, Santamaría J, Monjardín A, et al. Dexamethasone increases eNOS gene expression and prevents renal vasoconstriction induced by cyclosporin. Am J Physiol. 1999; 277(3):F464-71. PMID: 10484530

28. Hafezi-Moghadam A, Simoncini T, Yang Z, Limbourg FP, Plumier J-C, Rebsamen MC, et al. Acute cardiovascular protective effects of corticosteroids are mediated by non-transcriptional activation of endothelial nitric oxide synthase. Nat Med. 2002; 8(5):473-9. PMID: 11984591

29. Rubio-Gayosso I, Platts SH, Duling BR. Reactive oxygen species mediate modification of glycocalyx during ischemiareperfusion injury. Am J Physiol Heart Circ Physiol. 2006; 290(6):H2247-56. PMID: 16399871

30. Greenwald RA, Moak SA. Degradation of hyaluronic acid by polymorphonuclear leukocytes. Inflammation. 1986; 10(1):15-30. PMID: 3007353

31. Taghizadieh M, Hajipour B, Asl NA, Khodadadi Ali SM. Coadministration of melatonin and dexamethasone attenuates lung tissue injury after liver ischemia/reperfusion. Life Sci J. 2013; $10(6 s): 314-20$ 